\title{
An Evaluation of Organizational Culture as Regressor of Accounting Procedure: A Case Study at National Investment Bank, Western Region of Ghana
}

\author{
Abigail Padi $^{{ }^{*}} \quad$ Emmanuel Boadi ${ }^{2}$ \\ 1.Faculty of Business Studies, Department of Accounting and Finance, Takoradi Technical University, P. O Box \\ 256, Takoradi, Western Region, Ghana \\ 2.Directorate of Finance, Takoradi Technical University, P. O Box 256, Takoradi, Western Region, Ghana
}

\begin{abstract}
The purpose of the study was to investigate the effect of organisational culture on accounting procedures at National Investment Bank (NIB), focusing on the various branches in the Western Region of Ghana. The study adopted the quantitative approach. The design employed the descriptive survey design. The study population was 62 permanent staff who were all considered for the study using the census method. Auxiliary employees such as cleaners, security staff and drivers were not considered. Questionnaire with a reliability coefficient of 0.857 was the instrument used. The data were analysed using means, standard deviations, and linear multiple regression analysis. The findings show that staff of the bank perceived the organisational culture of the bank positively. Also, staffs were satisfied with the culture of the bank. The study found that though NIB's organisational culture relates positively to staff level of satisfaction; it does not predict accounting procedures of the bank strongly. It does so through staff level of satisfaction. The study, therefore, conclude that organisational culture of the bank has significant influence on the bank's adopted accounting procedures. It is recommended to board of directors and management of the bank to ensure that the bank nurture and regularised the internal control culture and roles of staff appropriately through the bank's strategic planning. This will lead to high level of staff satisfaction in the bank's culture. This condition will in the long run lead to the general improvement in the accounting procedures of the bank.
\end{abstract}

Keywords: Accounting procedures, Bank, Organisational culture, Staff satisfaction

DOI: $10.7176 / \mathrm{EJBM} / 12-27-10$

Publication date:September $30^{\text {th }} 2020$

\subsection{Introduction}

Culture at the workplace, is a very potent force, which is planned and natured among new entrance upon their arrival. It is the very fibre that holds the organisation in concert. The weight of organisational culture is emphasised by Bailey (2009), who state that, without exception, the pre-eminence and steadiness of culture proved to be an indispensable quality of the first-rate organisation, banks inclusive. In organisations with strong culture, subordinates know what they are supposed to do in most situations because the handful of guiding values is crystal clear. Organisational culture can be seen as a set of beliefs, values, work styles and relationships that distinguish one organisation from another. It can also be seen as the sum of patterns of common convictions, rituals, fables and sentiments that become collectively acceptable from members of an organisation (Paramita, Lumbanraja \& Absah, 2020).

Generally, it is considered to be an important factor affecting organisational success or failure (Belias \& Koustelios, 2014). According to Cheema and Abbas (2017), it is frequently held accountable for organisational ills and, on occasions, praised for creating positive qualities. Standards within organisations are determined largely by the culture of the organisation. Likewise, the financial regulations, accounting procedures, and internal control systems of organisations are determined by the culture of the organisation (Paramita et al., 2020). This means, the way of doing things in the organisation is the culture of the organisation.

Many banks believe that their culture defines and shapes their direction in attaining their mission through a set of established values, and also boost staff satisfaction. Nonetheless, deep differences exist between such beliefs and the actual effects of a bank's culture (Maina, 2016). These differences impact on overall optimised results through the identification of the bank's core values. In relation to accounting procedures and practices, Saani (2019) indicated that there are best and internationally accepted practices that are intrinsic in the culture of all banks. However, compliance with these international accounting procedures does vary significantly among organisations within the banking sector (Hooi, 2017). It is therefore, appropriate for one to find out the reasons behind the differences in accounting procedures and also to examine the extent to which their way of doing things influence their accounting procedures.

An effective accounting procedures supported by strong governance, and sound regulatory framework are significant to economic development. High accounting procedures underpin the trust that investors place in financial information and thus, play an integral role in contributing to a countries economic growth and financial 
stability. In view of this many countries and organisations have developed in the public interest a single set of high quality, understandable and enforceable accounting procedures that require transparent and comparable information in general purpose financial statement (Saani, 2019).

In its quest to promote accelerated growth through private sector-led, government of Ghana has directed organisations to adopt appropriate accounting procedures (Saani, 2019). However, effective accounting procedures do not exist in a vacuum, but operates in an environment characterised by a specific culture. The call for studying accounting culture within its environmental context has been suggested by many scholars (Chukwu, Aguwamba \& Kanu, 2017; Saani, 2019). According to Saani (2019), such a call is mainly stimulated by a belief that accounting is a socially constructed reality; therefore, financial reporting practice cannot be separated from its cultural context. Indeed, culture plays important roles in constructing social structure and institutions (Dio, Darma, Febrianti \& Mirwansyah, 2020).

Consequently, culture may influence the accounting procedures of a company. However, there are currently culture issues that affect National Investment Bank (NIB) and other banks in Ghana. Some of these issues had to do with poor orientation, undefined roles among middle level staff, poor achievement indicators, and poor control measures as a result of favouritism, ethnocentrism and nepotism (Saani, 2019). Nevertheless, empirical studies have not provided conclusive and convincing evidence to support the claims made for the usefulness of accounting procedures and good organisational culture. The examinations to date have all but ignored the role organisational culture play in accounting procedures. The aim of this study is therefore, to contribute to an understanding of the influence of organisational culture on accounting procedures at NIB, focusing on the various branches in the Western Region of Ghana.

The objective of the study was to investigate the different dimensions of organisational culture in the workplace in relation to their influence on accounting procedures at NIB, focusing on the various branches of the bank in the Western Region of Ghana. The specific objectives of the study were to:

- $\quad$ examine the dimensions of organisational culture in NIB, Western Region; and

- $\quad$ assess the effect of organisational culture of NIB, Western Region on the bank's accounting procedures.

The purpose of the study is to fill up significant gaps in the literature on organisational culture and accounting procedures in the context of developing countries like Ghana. The findings of the study when implemented would help management and finance officers of NIB, Western Region not only to be able to understand and deal with the bureaucratic systems in the financial system of the bank but also identify the usefulness of the bank's culture and its influence on accounting procedures of the bank. In addition, the results of this study would also serve as a guide for administrators and financial officers in the banking sector to vary their approach and methodology in order to adapt to the culture and accounting procedures within the banking industry, and to improve service delivery in the country.

With regard to geographical area, the study was delimited to NIB, Western Region. In relation to elements, the study focused on all permanent staff and management of NIB, Western Region who are involved in the accounting and finances of the bank. The study further focused on two main variables: organisational culture and accounting procedures. The organisational culture variable was delimited to four dimensions: control, role, outcome and orientation while the accounting procedures variable was delimited to five facets: control environment, risk assessment, control activities, information and communication, and monitoring.

\subsection{Conceptual Framework}

Several theories have been formulated to show the inherent connection between organisational culture and accounting procedures. Some theoretical models assert that organisational culture create a positive impact on employees' satisfaction and behaviours which in turn influence their effectiveness. In this study, the Schein's theory of organisational culture was used to underpin the argument of the study. Schein's theory of organisational culture consists of three domains: basic underlying assumptions, espoused values, and artifacts. The argument of the theory is that the bank's products, physical environment, language, technology, clothing, myths and stories, published values, rituals and ceremonies must all work to build and develop the bank's culture (Maina, 2016). This in the long run will help boost staff satisfaction in the culture of the bank which will in turn help hence their accounting procedures in the bank.

Based on the argument of the theory, the study adopted four components of organisational culture: control, role, outcome, and orientation. Also, in relation to accounting procedures, four components were considered: control environment, risk assessment, control activities, and monitoring of controls. The four components of organisational culture adopted are in line with that of Saani (2019) while that of accounting procedures are in line with that of Dineshkumar and Kogulacumar (2017). The study also introduced a moderator to see its effects on the bank's accounting procedures. Some staff of most banks in Ghana easily gets further up with respect to their satisfaction to the work they do at the bank (Saani, 2019). The researchers inclined to think that whenever the various forms of organisational culture adopted by the bank get employees to be satisfied with their work, it makes them develop sense of belongingness to what the bank stand for. When that happens, it may translate into increase 
in the effectiveness of the accounting procedures of the bank in the long run. The link between the independent (four organisational culture dimensions), moderating (satisfaction), and dependent (accounting procedures) variables is illustrated in Figure 1.

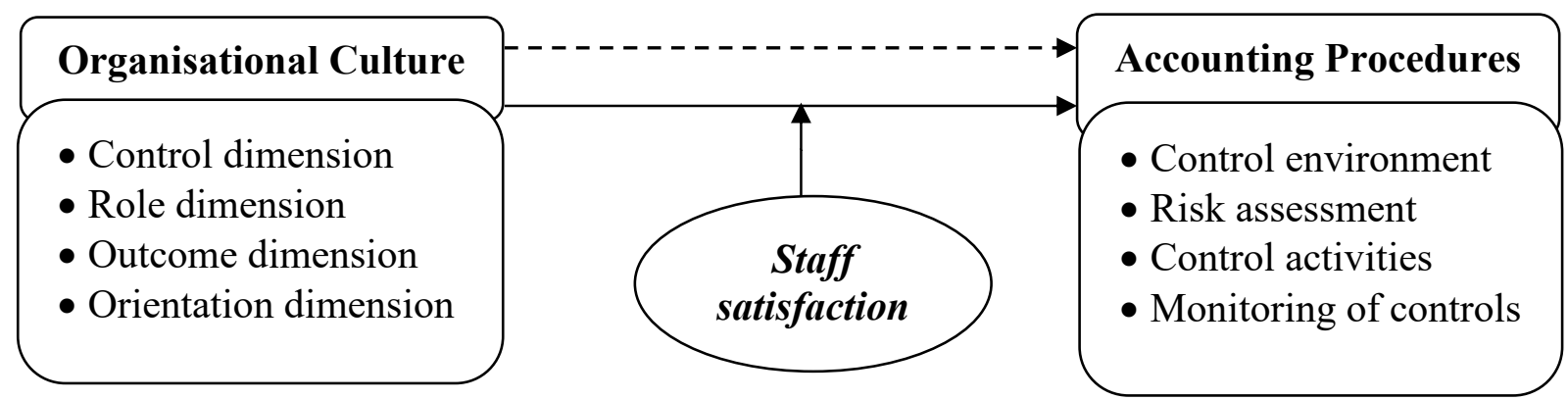

Figure 1: Organizational culture as regressor of accounting procedure

Source: Adapted from Dineshkumar and Kogulacumar (2017) and Saani (2019)

The argument of the study is that, the four main components of organisational culture when adopted and implemented effectively as expected, are likely to induce employees' satisfaction with the work they do at the bank. With these control culture strategies in place, employees are likely to feel more satisfied and see themselves as accepted members of the bank. They will develop the desire to belong and be an important part of the bank. These variables may also strengthen the internal dynamics of the bank which will then lead to staff satisfaction. In other words, strengthening or improving the various adopted organisational culture dimensions of the bank will lead to an inducement of employees' satisfaction in the bank with regard to their work, which will intend improve the accounting procedures of the bank in the long run.

\subsection{Research Methodology}

The descriptive survey design was employed for this study. This design was used because the study entailed a survey of staff perception of the issues, situations and processes. The target population for the study was all staff of NIB Ghana limited while the accessible population was all staff of NIB in the Western Region of Ghana. Current data available to the researcher show that there are 62 permanent staffs of the bank in the region. This number excludes auxiliary employees such as cleaners, security staff and drivers. Due to the small number of staff at NIB in the Western Region of Ghana, the census method was deemed proper and doable. The census method was also employed because staffs of the bank were quite different from each other in terms of qualification, gender, experience and responsibilities. Most researchers are of the view that it is always appropriate to use the census method in a study with relatively small and variable population (Kelly, 2016).

Questionnaire with a reliability coefficient of 0.857 , was the instrument used to collect the data. Prior to the administration of the questionnaire, an informal familiarisation visits were made to the various branches of the bank in the region to confirm respondents participation. The questionnaires were administered personally by the researchers with the support of known staff. The data collection procedures were carried out in three stages. The first stage was the collection of list of respondents. The second stage was the distribution of the questionnaire to respondents while the third stage focused on retrieving of the questionnaire administered to the respondents. At the end of data collection, the researcher was able to collect all the 62 questionnaires administered. This resulted in 100 percent response rate.

Data on the first specific objectives were analysed using means and standard deviation since the distribution was normal while data on the second specific objectives were analysed using linear multiple regression analysis. The linear multiple regression analysis was used to determine if the explanatory variables explain a substantial proportion of the variance in the effectiveness of accounting procedures of the bank. According to Darren and Mallery (2014), to find out the influence of independent variables on a dependent variable, where both variables are measured using discrete scale and the distribution is normal, it is appropriate to use the linear multiple regression analysis.

\subsection{Results and Discussion}

The rationale for the first specific objective of the study was to know the perceptions of staff on the organisational culture of the bank in order to find out which of the dimensions of organisational culture are highly perceive and the one that is lowly perceived. The perceptions of the staff on organisational culture were described in terms of means and standard deviations. The results are presented in Table 1. 
Table 1: Respondents' Perceptions on Organisational Culture of the Bank

\begin{tabular}{lccc}
\hline Dimensions of organisational culture & Mean & Std. Dev. & Scales \\
\hline Control dimension & 4.25 & 0.56 & $1-5$ \\
Role dimension & 4.10 & 0.47 & $1-5$ \\
Outcomes dimension & 4.16 & 0.56 & $1-5$ \\
Orientation dimension & 3.99 & 0.41 & $1-5$ \\
\hline Source: Fie
\end{tabular}

Source: Field data, 2020

Where Std. Dev. = standard deviation.

$(\mathrm{N}=62)$

As indicated in Table 1, respondents perceived control (Mean $=4.25$, Std. Dev. $=0.56)$ (with the highest mean scores) to be the most dominant organisation culture dimension they consider most, followed by outcomes $($ Mean $=4.16$, Std. Dev. = 0.56), role $($ Mean = 4.10, Std. Dev. =0.47) and staff orientation $($ Mean = 3.99, Std. Dev. $=0.41)$. All the features were rated moderately in positive terms with regard to staff view on organisational culture. Staff orientation (Mean $=3.99$, Std. Dev. $=0.41$ ) with the lowest mean score was perceived on the overall as least feature that respondents consider. However, the degree of respondents' perception on the dimensions of organisational culture was largely positive. Therefore, staff of NIB in the Western Region perceived the culture of the bank positively. The standard deviations were moderate, indicating the non-dispersion in a widely-spread distribution. This means the views of the staff were coming from a moderate homogeneous group that is, a group with similar characteristics.

The findings show that staffs were in favour of the organisational culture of the bank. This finding supports the submission made by Maina (2016) that for staff to be satisfied in a bank, they must first perceive the bank's culture in positive terms. Also, findings are congruent with the comments of Hooi (2017) who posits that most staff perceive their organisations' culture practices positively, especially where the corporate culture of the organisation are non-personal and standard. Hooi added that the degree to which organisations' conditions foster the development of employees, allows scope for growth and application of new ideas and methods to solve particular problems are lacking in most organisations. However, some organisations continue to provide meaningful level of stimulation and support to employees. This shows that if there is a sense of team spirit among the members of the bank, the culture is likely to be perceived as considerate, warm and supportive.

The rationale of the second specific objective of the study was to assess the effect of organisational culture of NIB, Western Region on the bank's accounting procedures. Multiple regression analysis procedures were adopted to analyse the data. Organisational culture of banks and the implementation of effective accounting procedures in the banking industry have come under attack but the literature fails to establish a link between these two variables. The study is of the view that the link between these two variables is mediated by staff level of satisfaction in the organisational culture of the bank. In dealing with this objective, the researchers first conducted preliminary analysis which shows that the data meet the colloniarity and homogeneity conditions. First, accounting procedures was used as the dependent variable while dimensions of organisational culture were treated as independent variables. Staff level of satisfaction in the bank's culture was treated as a moderator. Results of the analysis are shown in Tables 2 and 3.

Table 2: First Model on the Effect of Organisational Culture on Accounting Procedures

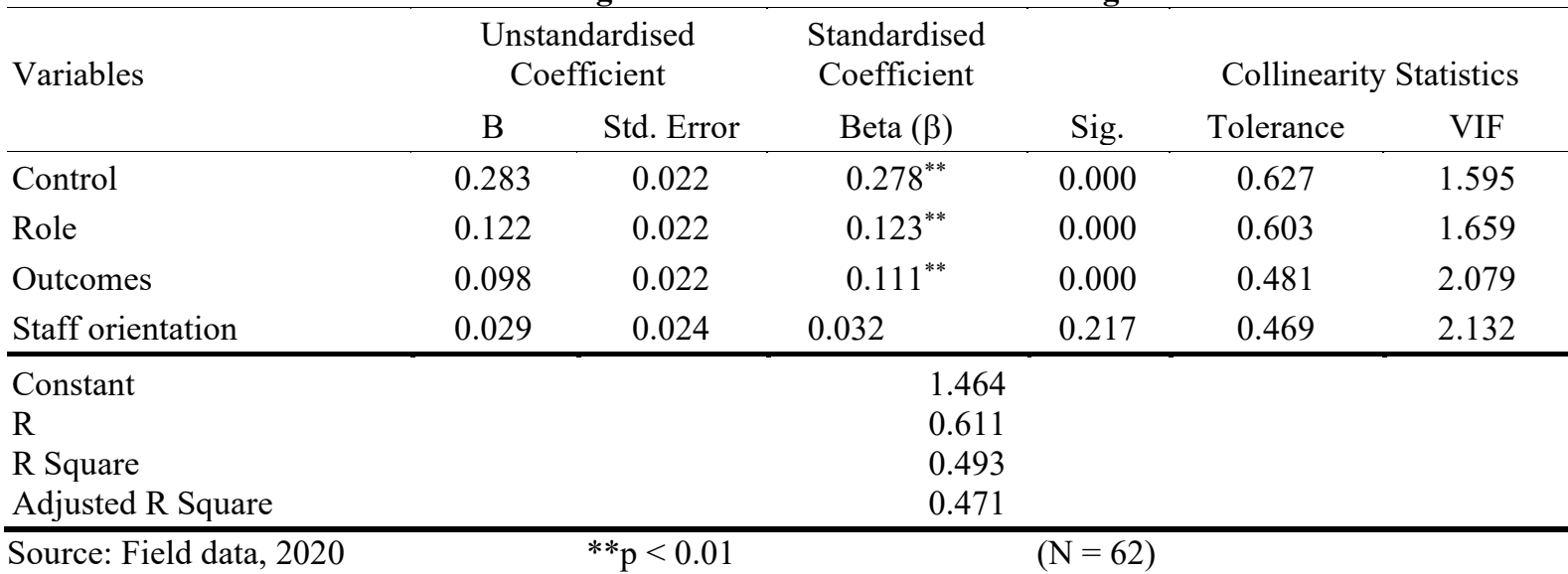

Source: Field data, 2020

Dependent Variable: Accounting Procedures

The multiple regression analysis involved testing of two models. In the first model the four features of organisational culture were entered as independent variables. As indicated in Table 2, three variables had significant association with accounting procedures of the bank at 0.01 significance level. However, staff orientation was not significant. The table show that the variables that predict the bank's accounting procedures in order of importance are control $(\beta=0.278, p<0.01)$, role $(\beta=0.123, p<0.01)$, outcomes $(\beta=0.111, p<0.01)$. The finding that staff orientation has no statistically significant effect on accounting procedures of the bank is 
congruent with that of Hooi (2017) who found out that long-term orientation is found to be a non-significant cultural value with banking disclosures. According to Hooi, the only significant cultural dimension is uncertainty avoidance. The study also found that the use of disclosure rate tends to yield slightly better results in terms of explanatory power compared to disclosure band.

It is, however, significant to observe that the proportional contribution of the four dimensions of organisational culture to accounting procedures of the bank is 0.493 with an adjusted $R^{2}$ of 0.471 . This means that organisational culture of the bank is able to explain 49.3 percent of the variance in accounting procedures of the bank. It therefore, means that besides these variables identified, other variables not yet in the model have a chance of contributing 50.7 percent to accounting procedures of the bank. The findings may mean that when there are rules and regulations that guide staff in their work and behaviour, when both staff and customers are conversant with the rules and regulations of the bank, and also when the rules and regulations of the bank are reviewed from time to time to make them relevant to the community's values, the accounting procedures of the bank becomes more significant and productive to the staff, customers and the bank as a whole. Similarly, when employees of the bank clearly understand what they are supposed to do and what they are not supposed to do, when employees of the bank relate cordially to one another, when there are clearly defined channels of communication in the bank, and when responsibilities and roles are equitably shared in the bank, it will produce accounting procedures that are more effective and productive to the bank.

Furthermore, accounting procedures of the bank become more productive when employees of the bank always aim at working to achieve the best of results, when hardworking staff and loyal customers are recognised, and when staff who come out with new ideas are encouraged. Likewise, when the orientation given to new staff and customers are affective, the accounting procedures of the bank will be adhere to by these staff and customers effectively which in the long run may lead to a significant increase in the finances of the bank.

As presented in Table 3, in the second model job satisfaction was entered into the equation to serve as a moderator. The theory here is that the independent variables do not predict the bank's accounting procedures directly and that they do so indirectly through staff level of satisfaction with the bank's culture. When the variable job satisfaction entered the equation the beta coefficients of all the significant variables shrank. The percentage changes accounting for the shrinkage are control (14.7\%), role (64.2) and outcomes $(3.6 \%)$. The beta coefficient of staff orientation which was non-statistically significant in the first model became significant.

Table 3 further show that staff level of satisfaction $(\beta=0.377, p<0.01)$ was statistically significant when it was entered into the first model, which did change the beta coefficients of other significant variables in the second model. What all the resultant shrinkages and statistically non significance mean is that the various dimensions of organisational culture predict accounting procedures of the bank more when staff are satisfied with the culture of the bank. In other words, the four independent variables in themselves do not explain significantly accounting procedures of the bank directly, they do so only when staff are satisfied with the culture of the bank.

Table 3: Second Model on the Effect of Organisational Culture on Accounting Procedures

\begin{tabular}{|c|c|c|c|c|c|c|}
\hline \multirow[b]{2}{*}{ Variables } & \multicolumn{2}{|c|}{$\begin{array}{c}\text { Unstandardised } \\
\text { Coefficient }\end{array}$} & \multirow{2}{*}{$\begin{array}{c}\text { Standardised } \\
\text { Coefficient } \\
\text { Beta }(\beta)\end{array}$} & \multirow[b]{2}{*}{ Sig. } & \multicolumn{2}{|c|}{ Collinearity Statistics } \\
\hline & B & Std. Error & & & Tolerance & VIF \\
\hline Control & 0.223 & 0.057 & $0.237^{* *}$ & 0.000 & 0.753 & 1.329 \\
\hline Role & 0.046 & 0.025 & $0.044^{*}$ & 0.016 & 0.527 & 1.896 \\
\hline Outcomes & 0.186 & 0.053 & $0.107^{* *}$ & 0.001 & 0.743 & 1.346 \\
\hline Staff orientation & 0.097 & 0.046 & $0.098^{* *}$ & 0.001 & 0.752 & 1.329 \\
\hline Job satisfaction & 0.382 & 0.022 & $0.377^{* *}$ & 0.000 & 0.627 & 1.596 \\
\hline Constant & & & 0.746 & & & \\
\hline $\mathrm{R}$ & & & 0.893 & & & \\
\hline R Square & & & 0.797 & & & \\
\hline Adjusted R Square & & & 0.784 & & & \\
\hline
\end{tabular}

\begin{tabular}{llll}
\hline Source: Field data, 2018 & $* * \mathrm{p}<0.01$ & $* \mathrm{p}<0.05$ & $(\mathrm{~N}=62)$
\end{tabular}

Dependent Variable: Accounting Procedures

As depicted in Table 3, there was a significant increase with regard to the proportional contribution $\left(\mathrm{R}^{2}\right)$ of all the entered variables, including job satisfaction to the dependent variable. It increased from 0.493 to 0.797 with an adjusted $\mathrm{R}^{2}$ of 0.784 , which means that when organisational culture is present, its predictability of accounting procedures of the bank becomes more potent when staffs are satisfied with the culture of the bank. The rate of change regarding the $\mathrm{R}$ square was 38.1 percent. This shows that staff level of satisfaction in the culture of the bank is a key factor that organisational culture of the bank must complement to produce effective accounting procedures. 
This confirms the findings of Paramita et al. (2020) that organisational cultures which have strong norms for control, role, outcomes, internalisation and identification are likely to generate high levels of staff job satisfaction and commitment to work. This means, when job satisfaction of employees is high, then the culture of the organisation becomes more potent as predictors of commitment. Also, the more staffs are satisfied with the culture of the organisation, the more established or correct way the organisation's activities, practices, and professionalism are done effectively for financial purposes. As it has been specified some time recently, accounting procedures are basic segment of a bank's administration and an establishment for its sheltered and sound operations (Hooi, 2017). Generally, organisations with effective accounting procedures are seen to be essentially bigger, more profoundly controlled, more aggressive, more productive, more fluid, more traditionalist in their bookkeeping strategies, more capable in their administration and bookkeeping, and subject to better administration controls.

Furthermore, the findings support that of Maina (2016) who concluded that commercial banks had organisation culture that determined how things were done, employees were like-minded and held similar beliefs and values, commercial banks were guided by values of consistency, adaptability and effective communication system, employees had a sense of identity which increased their satisfaction in what they do, and commercial banks had clearly spelt out work ethics. Also, the findings that control, role, outcome, and staff orientation, which are dimensions of organisational culture, have positive impact on accounting procedures of the bank supports the comment of Saani (2019) who posits that risk and control mindfulness have an impact on the extent of the accounting procedures adopted by an institution. At the point when administration knows about dangers and control exercises, they will probably comprehend the part of the accounting procedures in observing danger and control exercises; along these lines it is more probable that they will bolster generally bigger procedural systems (Saani, 2019).

\subsection{Conclusions}

Staffs of NIB in the Western Region of Ghana are happy with the distinctive pattern of shared assumptions, values and norms that shape the socialisation activities, language, symbols, rites and ceremonies of the bank and its staff and customers. That is, they have positive perception of the organisational culture of the bank. However, the organisational culture of the bank does not influence the correct way the bank's activities, practices, and professionalism are done effectively for financial purposes strongly. It does so only if it boosts staff level of satisfaction in the organisational culture of the bank. If staff of the bank are satisfied with the bank's way of doing things, they are likely to develop high level of sense of belongingness to the bank which will in turn ignite them to established or do things correctly to ensure effectiveness in the financial purposes of the bank with regard to their activities and professionalism.

Whenever the dimensions of organisational culture of the bank get staff to be satisfied with their job in the bank, it makes them committed to what the bank stands for. When that happens and there is critical mass of employees who are satisfied with the organisational culture of the bank, it will translate into the adaption of correct way the bank's activities, practices, and professionalism are done effectively for financial purposes. Therefore, to ensure that there are appropriate accounting procedures in the banking industry, banks must nurture the kind of atmosphere that will make staff satisfied with the culture of the banks and the industry at large. This will influence the staff to ensure that the institutional objectives of the banks are realised.

\section{References}

Bailey, T. L. (2009). Organisational culture, macro and micro empowerment dimensions, and job satisfaction: An application of current mixed and multi-level methods in the federal sector. Florida: Boca Raton.

Belias, D., \& Koustelios, A. (2014). Organisational culture and job satisfaction: A review (Electronic version). International Review of Management and Marketing, 4(2), 132-149. Retrieved May 12, 2020, from www.econjournals.com

Cheema, A. M., \& Abbas, M. (2017). Organisational culture impact on banking performance in presence of organisational commitment: A case of banking sector of Pakistan (Electronic version). International Journal of Applied Business and Economic Research, 15(18), 67-83. Retrieved March 12, 2020, from http: www.serialsjournal.com

Chukwu, B. A., Aguwamba, S. M., \& Kanu, E. C. (2017). The impact of organisational culture on performance of banking industry in Nigeria. International Journal of Economics, Commerce and Management, 5(4), 201214. Retrieved March 23, 2020, from http://ijecm.co.uk/

Darren, G., \& Mallery, P. (2014). SPSS for Window - Step by step: A simple guide and reference ( $5^{\text {th }}$ ed.). New York: Oak Press.

Dineshkumar, S., \& Kogulacumar, P. (2017). Accounting procedures and its impact on the performance of the Sri Lanka Telecom limited in Jaffna district. International Journal of Advanced Computer Technology, 6(6), 5663.

Dio, P., Darma, C., Febrianti, W., \& Mirwansyah, D. (2020). Exploration of leadership, organisational culture, job 
satisfaction, and employee performance (Electronic version). Technium Social Sciences Journal, 6, 116-130. Retrieved May 27, 2020, from www.techniumscience.com

Hooi, G. (2017). The effects of culture on international banking disclosures. Asia-Pacific Journal of Accounting and Economics, 24(1), 7-25.

Kelly, A. P. (2016). Social research methods. London: University of London.

Maina, J. (2016). Influence of organisational culture on performance of Commercial banks in Kenya. Published master's thesis, School of Business. University of Nairobi, Nairobi.

Paramita, E., Lumbanraja, P., \& Absah, Y. (2020). The influence of organisational culture and organisational commitment on employee performance and job satisfaction as a moderating variable at PT. Bank Mandiri (Persero), Tbk. International Journal of Research and Review, 7(3), 273-286. Retrieved May 23, 2020, from www.ijrrjournal.com

Saani, A-J. (2019). Influence of organisational culture on banks' financial regulations: The case of selected commercial banks in Ghana. IUG Journal of Business and Social Sciences, 3(1), 12-27. 